\title{
PORQUE SAÚDE AMBIENTAL TAMBÉM É UMA QUESTÃO DE EDUCAÇÃO
}

\author{
Why environmental health is also a question of education
}

\author{
Emanuele Brusamarelo ${ }^{1}$ \\ Daniela Brusamarelo² \\ Júlia Larissa Ferreira dos Santos ${ }^{3}$ \\ Janaina Carla da Silva Simão Pereira ${ }^{4}$
}

RESUMO: Os processos produtivos impactam diretamente a saúde ambiental e do trabalhador. O uso intensivo de agrotóxicos nas culturas garante maior produtividade por hectare. A presença de resíduos de agrotóxicos em água para o consumo, e em alimentos, excede a preocupação local, e integram assunto de ordem global. Nessa perspectiva, a utilização massiva de agrotóxicos nas culturas deveria ser preocupação e pauta de debate entre gestores públicos, empresas privadas, organizações e sociedade civil. A certeza de que o homem impacta o ambiente e por ele é impactado consiste em justificativa para abordagem crítica da saúde ambiental no ensino formal e não-formal. A partir do ponto de vista reflexivo e crítico abordaremos algumas preocupações e caminhos direcionados à forma como os processos de produção, relacionados ao uso e aos agravos dos agrotóxicos, interferem sobremaneira na saúde do ambiente e apresentam demandas à educação.

Palavras-chave: Ambiente. Saúde. Educação.

ABSTRACT: The productive processes directly impact the environmental and worker health. The intensive use of pesticides in crops ensures greater productivity per hectare. The presence of pesticide residues in water for consumption, and in food, exceeds local concern, and are part of a global issue. In this perspective, the massive use of pesticides in crops should be a concern and debate among public managers, private companies, organizations and civil society. The certainty that man impacts the environment and is impacted by it is a justification for a critical approach to environmental health in the formal and non-formal education. From a critical and

\footnotetext{
${ }^{1}$ Zootecnista. Doutoranda do Programa de Pós-Graduação em Ciência Animal. Universidade Federal de Mato Grosso - Câmpus Cuiabá. E-mail: brusamareloemanuele@gmail.com.

2 Professora da Educação Básica. Mestra em Educação para Ciências e Matemática. Instituto Federal de Educação, Ciência e Tecnologia de Goiás - Câmpus Jataí. Email: dankerberos@hotmail.com.

${ }^{3}$ Fonoaudióloga. Especialista em Audiologia, Faculdade de Estudos Administrativos - Minas Gerais.

${ }^{4}$ Enfermeira, Especialista em Auditoria em Serviços de Saúde, Gestão Estratégica e Políticas em Saúde - Cursos de Pós-Graduação e Extensão - Cuiabá.
} 
critical point of view, we will address some concerns and paths directed at how the production processes, related to the use and aggravation of pesticides, interfere greatly in the health of the environment and presents demand on education.

Keywords: Environment; Health; Education.

\section{INTRODUÇÃO}

O Brasil se configura como importante fronteira agrícola no cenário mundial, com destaque para a região centro-oeste e o Estado de Mato Grosso, que é considerado referência na produção de grãos. As culturas da soja, do milho, do algodão e do arroz se estendem nessa região e impulsionam o agronegócio, caracterizado pela presença de grandes corporações detentoras de capital de constituição nacional ou multinacional.

Ao percorrer os principais municípios produtores de grãos, não raro o cenário que encontramos é o das plantações "invadindo" o espaço urbano. Em algumas cidades é comum de um lado, observarmos a avenida principal, e do outro lado grandes plantações de algodão, de milho, de soja, de cana-de-açúcar.

A economia em âmbito global, por sua vez pautada no sistema, baseia-se na produção de bens e produtos em grande escala por meio da exploração desenfreada dos recursos naturais, na produção e no consumo, no acúmulo de capital para grupos minoritários. Nessa conjuntura, o agronegócio brasileiro assume importância vital na economia do país e, para atender a objetivos e interesses diversos, a fronteira agricultura tem sido ampliada continuamente por meio da implementação e da aplicação de estratégias tecnológicas.

Dentre as transformações decorrentes no meio agrícola são observados os solos cada vez mais exauridos; as culturas transgênicas em substituição as produções agrícolas tradicionais; a escassez de sementes orgânicas; a crescente demanda por agrotóxicos; as plantas invasoras que se tornam mais resistentes pelo excesso de tais produtos; as nascentes e mananciais poluídos. Tais transformações do espaço natural pelo homem impactam de forma insustentável o ambiente, de modo a atender aos interesses do mercado, controlado por grandes corporações.

Com o entendimento de que o ambiente é um sistema complexo, ou seja, um conjunto que integra a dimensão social, a econômica, a política, a ambiental, as 
quais interagem entre si e são interconectadas com o todo, podemos perceber a abrangência do impacto ambiental ocasionado pela utilização de agrotóxicos.

Esse cenário apresenta demandas para a educação comprometida com a formação de cidadãos críticos diante das relações sociais e econômicas de seu tempo, e atuantes na transformação da realidade com vistas à sustentabilidade da relação sociedade-economia-natureza e a melhora da qualidade de vida. Dessa forma, o objetivo deste artigo de revisão é o de apontar inquietações relacionadas à forma como os processos de produção agrícola utilizando agrotóxicos interferem na saúde ambiental e do trabalhador e as demandas que esse contexto apresenta à educação.

\section{A PROBLEMÁTICA DA UTILIZAÇÃO MASSIVA DE AGROTÓXICO}

Efetivamente, a problemática já se encontra nos lares, no uso doméstico feito por donas de casa, sitiantes e agricultor familiar que compram o agrotóxico no mercado com o intuito de "matar" as plantas invasoras do quintal ou das suas plantações. A facilidade para aquisição e a variedade de princípios ativos disponíveis no mercado é motivo crescente de preocupação em função da potencialidade de acidentes, principalmente às intoxicações clínicas e subclínicas de humanos e de animais.

O crescente uso de agrotóxicos na produção agrícola e a consequente presença de resíduos acima dos níveis autorizados nos alimentos têm sido motivo de preocupação. No âmbito da saúde pública, exige das diversas esferas de governo, investimento e organização para a implementação de ações de controle do uso massivo de agrotóxicos (ANVISA, 2013) ${ }^{5}$.

A aplicação de agrotóxicos é uma atividade em que a contaminação do ambiente de trabalho é intencional, ou seja, uma finalidade sendo provocada pelos indivíduos, "no intuito de combater as pragas da lavoura" (PIGNATI; MACHADO;

\footnotetext{
${ }^{5}$ AGÊNCIA NACIONAL DE VIGILÂNCIA SANITÁRIA-ANVISA. Programa de Análise de Resíduos de Agrotóxicos em Alimentos (PARA). Relatório de Atividades de 2011 e 2012. Brasília, out., 2013. 45p. Disponível <http://portal.anvisa.gov.br/documents/111215/117818/Relat\%25C3\%25B3rio\%252BPARA\%252B201 1-12\%252B-\%252B30_10_13_1.pdf/d5e91ef0-4235-4872-b180-99610507d8d5>. Acesso em: 09 dezembro 2016.
} 
CABRAL, 2007, p. 108) ${ }^{6}$. Nesse viés, os autores destacam que o mais grave disto é que, na agricultura, o ambiente de trabalho é o próprio ambiente em que se vive, com o qual se está em interação direta. Assim, a contaminação, que ocorre em diferentes níveis, atinge o espaço natural, o trabalhador, a própria produção e os consumidores. Portanto, sendo o ambiente um sistema complexo, os impactos sofridos por este são devolvidos ao homem com implicações diversas.

A propósito do solo, este é o destino final dos produtos químicos usados na agricultura, sejam eles aplicados diretamente no solo ou nas partes aéreas das plantas. De acordo com Mancuso, Negrisoli e Perin $(2011)^{7}$, os herbicidas, ao entrarem em contato com o solo estão sujeitos a processos físico-químicos que regulam o seu destino no ambiente.

No que concerne à legislação brasileira atual, são previstas restrições ao uso, compra, dispensa e registro dos agrotóxicos. Porém, tem-se dificuldade no cumprimento fidedigno em função da precariedade na fiscalização das ações para combater o uso e a manipulação incorreta desses princípios ativos majoritariamente tóxicos e letais a qualquer organismo vivo. Os agrotóxicos são produtos que provocam agravos à saúde, haja vista a sua potencialidade de toxicidade que estão em função dos diferentes princípios ativos.

O Limite Máximo de Resíduo (LMR) é um parâmetro agronômico, derivado de estudos de campo simulando o uso correto do agrotóxico pelo agricultor. Todavia, o LMR está relacionado com a segurança dos alimentos comercializados, quanto à presença de resíduos de agrotóxicos, e constitui um dos componentes para o cálculo da exposição e avaliação do risco dietético que antecede o registro de um agrotóxico ou a autorização da inclusão de novas culturas (ANVISA, 2016) ${ }^{8}$.

O uso excessivo de agrotóxicos, facilitado pela falta de fiscalização na compra e na utilização, somados a falta de capacitação para o manejo e a correta utilização dos princípios ativos comerciais disponíveis, promovem acidentes com intoxicações

\footnotetext{
${ }^{6}$ PIGNATI, W. A.; MACHADO, J. M. H.; CABRAL, J. F. Acidente rural ampliado: o caso das "chuvas"de agrotóxicos sobre a cidade de Lucas do Rio Verde - MT. Ciência \& Saúde Coletiva, v. 12, n. 1, p.105-114, 2007.

7 MANCUSO, M. A. C.; NEGRISOLI, E.; PERIM, L. Efeito residual de herbicidas no solo ("Carryover"). Revista Brasileira de Herbicidas, v. 10, n. 2, p. 151-164, mai./ago., 2011.

${ }^{8}$ AGÊNCIA NACIONAL DE VIGILÂNCIA SANITÁRIA-ANVISA. Programa de Análise de Resíduos de Agrotóxicos em Alimentos (PARA). Relatório das análises de amostras monitoradas no período de 2013 a 2015. Brasília, nov., 2016. 246p.

Disponívelem:<http://portal.anvisa.gov.br/documents/111215/0/Relat\%C3\%B3rio+PARA+20132015_V ERS\%C3\%83O-FINAL.pdf/494cd7c5-5408-4e6a-b0e5-5098cbf759f8>. Acesso em: 08 dezembro 2016.
} 
de manipuladores e até mesmo áreas urbanas inteiras. Um fator que contribui para esta problemática é a expansão agrícola que margeia os centros urbanos, bem como o processo inverso, o crescente processo de urbanização que adentra as áreas rurais.

A Lei de Agrotóxicos e Afins nำ 7.802/1989, regulamentada pelo Decreto ํㅜ 4.074/2002, define que os agrotóxicos são os

produtos e os agentes de processos físicos, químicos ou biológicos, destinados ao uso nos setores de produção, no armazenamento e beneficiamento de produtos agrícolas, nas pastagens, na proteção de florestas, nativas ou implantadas, e de outros ecossistemas e também de ambientes urbanos, hídricos e industriais, cuja finalidade seja alterar a composição da flora ou da fauna, a fim de preservá-las da ação danosa de seres vivos considerados nocivos (BRASIL, 1989, p. 1) ${ }^{9}$.

A Lei supracitada estabelece que os agrotóxicos somente poderão ser utilizados no país se forem registrados em órgão federal competente, de acordo com as diretrizes e exigências dos órgãos responsáveis pelos setores da saúde, do meio ambiente e da agricultura. Neste sentido, o Decreto nำ4.074/2002, que regulamenta a Lei, estabelece as competências para os três órgãos envolvidos no registro: a Agência Nacional de Vigilância Sanitária (ANVISA), vinculada ao Ministério da Saúde; o Instituto Brasileiro do Meio Ambiente e dos Recursos Naturais Renováveis (IBAMA), subordinado ao Ministério do Meio Ambiente; e o Ministério da Agricultura, Pecuária e Abastecimento (MAPA) (ANVISA, 2013).

\section{OS AGRAVOS DOS TÓXICOS}

Para além da legislação existente, a problemática da contaminação ambiental decorrente da utilização de agrotóxicos que excedem o tempo e o espaço das plantações tem se tornado motivo de preocupação nesta sociedade contemporânea, na dimensão local, regional e global. O excesso de agrotóxicos utilizados em hortaliças, leguminosas, tubérculos e frutas; a exposição humana no campo e nas

\footnotetext{
${ }^{9}$ BRASIL. Lei no 7.802, de 11 de julho de 1989. Dispõe sobre a pesquisa, a produção, a embalagem e rotulagem, o transporte, o armazenamento, a comercialização, a propaganda comercial, a utilização, a importação, a exportação, o destino final dos resíduos e embalagens, o registro, a classificação, o controle, a inspeção e a fiscalização de agrotóxicos, seus componentes e afins, e dá outras providências. In: Legislação federal de agrotóxicos e afins. Brasília (DF): Ministério da Agricultura e do Abastecimento; 1998. p. 7-13.
} 
cidades; as intoxicações de animais domésticos e da fauna são realidades inquietantes e que tem crescido.

Do mesmo modo, as plantações situadas próximas aos rios e as cidades também são fonte de exposição á agrotóxicos, em uma reação em cadeia. $A$ poluição da água dos rios afetará todo o ecossistema aquático daquela localidade, e o pior, impactando negativamente muitos quilômetros além dali.

Em relação à aplicação dos agrotóxicos, os métodos podem ser por via sólida, líquida e gasosa, dentre os quais a via líquida é o método predominante. $A$ via gasosa é empregada somente em alguns casos. Na aplicação por via líquida uma formulação é geralmente diluída em água, formando a chamada calda, que comumente é aplicada na forma de gotas através da pulverização. Para Spadotto $(2006)^{10}$, convém destacar que qualquer quantidade do agrotóxico que não atingir a peste-alvo terá efeito nulo e representará uma forma de perda e uma fonte de contaminação ambiental.

Assim, os diversos princípios ativos apresentam diferentes comportamentos nos distintos compartimentos ambientais, podendo ou não persistir e ser disperso no ambiente. É importante ressaltar que, de acordo com Palma e Lourencetti $(2011)^{11}$, além da diferença comportamental no ambiente, os agrotóxicos também apresentam graus variados de toxicidade para os humanos, os animais e os organismos aquáticos.

Para Mancuso, Negrisoli e Perin (2011) é importante considerar também que, dentre os processos envolvidos após a aplicação dos herbicidas sobre a planta-alvo, está a retenção (sorção (adsorção e absorção)), transformação (degradação química e/ou biológica), transporte (deriva, volatilização, lixiviação e escorrimento superficial) e a interação entre todos esses processos (Mancuso, Negrisoli \& Perim, 2011).

As diversas formas de uso e aplicação dos agrotóxicos seguem normas específicas quanto à distância mínima de cursos d'água, residências e outras plantações. Embora a extensão dos impactos causados ao ambiente não permita a sua mensuração, pois, em contato com a atmosfera, as moléculas podem ser transportadas por longas distâncias, atingindo áreas distantes dos locais de

\footnotetext{
10 SPADOTTO, C. A. Abordagem interdisciplinar na avaliação ambiental de agrotóxicos. Revista Núcleo de Pesquisa Interdisciplinar, São Manuel, p. 1-9, 2006.

${ }_{11}$ PALMA, D. C. A.; LOURENCETTI, C. Agrotóxicos em água e alimentos: risco à saúde humana.
} REVISTA UNIARA, v. 14, n. 2, p. 7-21, dez., 2011. 
aplicação, conforme evidenciado por Sanches et al. (2003) ${ }^{12}$, ao não respeitar as distâncias previstas por meio de leis e decretos os danos são potencializados.

Os herbicidas classificados como residuais são aqueles que apresentam maior período de atividade. Entretanto, Mancuso, Negrisoli e Perim (2011) afirmam que tais herbicidas podem apresentar efeito residual ou carry-over efeito, com potencial de impacto ambiental negativo. Portanto, esse efeito cumulativo do herbicida sobre os grãos, as folhas, os tubérculos que serão consumidos, os efeitos no local da produção e os que ultrapassam as fronteiras agrícolas tem preocupado sobremaneira a sociedade.

Uma ponderação aqui se faz necessária, pois, independente da forma de aplicação e de regras a serem seguidas quanto ao uso de agrotóxicos, a expansão da fronteira agrícola mundial continua a ocorrer. A economia, atrelada às grandes multinacionais da agricultura e da biotecnologia, transforma a agricultura, promove o aumento na produção de grãos, a utilização de grandes quantidades de agrotóxicos, impactando todas as formas de vida direta ou indiretamente.

Acerca dos acidentes envolvendo os agrotóxicos estão intrinsecamente relacionados ao efeito esperado destas substâncias (PIGNATI; MACHADO; CABRAL, 2007). A ecotoxicidade, assim como a toxicidade humana, seja aguda ou crônica, é variável entre os agrotóxicos. Os produtos muito tóxicos para um organismo podem não ser para outros. Além disso, organismos muito sensíveis a um dado agrotóxico podem não ser expostos a ele em concentrações ou em doses superiores aos níveis tóxicos. A exposição pode ser expressa como a ocorrência que é a presença do agrotóxico no habitat do organismo, ou como contato entre o agrotóxico e o organismo. Nesse sentido, Spadoto (2006) acrescenta que alguns organismos possuem capacidade de bioacumular substâncias químicas, caracterizando o processo de bioacumulação ou bioconcentração.

Os agravos à saúde ambiental e do trabalhador provocados pela utilização e manipulação incorreta dos agrotóxicos são realidade frequente e tem aumentado com a expansão das áreas agricultáveis e das lavouras transgênicas. Os dados de intoxicações provenientes dos diferentes agentes químicos usuais às plantações de grãos, de vegetais, de frutas e de folhas, que causam agravos à saúde do

\footnotetext{
12 SANCHES, S. M. et al. Pesticidas e seus respectivos riscos associados à contaminação da água.
} Pesticidas: Revista de Ecotoxicologia e Meio Ambiente, Curitiba, v. 13, p. 53-58, jan./dez., 2003. 
trabalhador e da população na maioria das vezes não são notificados pelos órgãos responsáveis.

O pesquisador da Universidade Federal de Mato Grosso (UFMT), Drº Wanderley Pignati, apresentou um panorama dos impactos ambientais e sanitários decorrentes do uso de agrotóxicos nos municípios de Mato Grosso, durante a Semana do Meio Ambiente promovida pelo Instituto Cidade Amiga. Durante o evento o prof. Dr. Pignati propõe lista de medidas para redução massiva do uso de agrotóxicos: proibição - como está sendo feito na união européia - das pulverizações aéreas de todos os tipos de agroquímicos; suspender os subsídios aos agrotóxicos em geral; monitorar a presença de resíduos de agrotóxicos, fertilizantes, metais e solventes em água potável, rios, lagos e pantanal; ampliar os financiamentos para a agroecologia e a produção de alimentos orgânicos; e investir em pesquisas voltadas ao controle biológico de pragas e às práticas sustentáveis de agropecuária (INSTITUTO CIDADE AMIGA, 2015) ${ }^{13}$.

Os resíduos de agrotóxicos em alimentos no Brasil têm preocupado estudiosos do tema e consumidores conscientes. O Programa de Análise de Resíduos de Agrotóxicos em Alimentos (PARA) foi iniciado em 2001 pela Agência Nacional de Vigilância Sanitária (ANVISA), com o objetivo de avaliar continuamente os níveis de resíduos de agrotóxicos nos alimentos de origem vegetal que chegam à mesa do consumidor, sendo um indicador da ocorrência de resíduos de agrotóxicos em alimentos.

De acordo com A ANVISA, no período de 2013 a 2015 o PARA analisou 12.051 amostras de 25 alimentos de origem vegetal divididos em cinco categorias: cereal/leguminosa; fruta; hortaliça folhosa; hortaliça não folhosa e raiz, tubérculo e bulbo. Foi observado que 9.680 amostras (80,3\%) foram consideradas satisfatórias quanto aos agrotóxicos pesquisados, sendo que em 5.062 (42,0\%) não foram detectados resíduos e 4.618 (38,3\%) apresentaram resíduos com concentrações iguais ou inferiores ao LMR. Do total analisado, 2.371 (19,7\%) amostras foram consideradas insatisfatórias (ANVISA, 2016).

Assim, se um resíduo de agrotóxico é encontrado em um alimento em concentração igual ou inferior ao LMR, o alimento pode ser considerado seguro para a saúde do consumidor, com relação a esse agrotóxico. No entanto, se um resíduo

\footnotetext{
${ }^{13}$ INSTITUTO CIDADE AMIGA. Pesquisador Wanderlei Pignati fala sobre impactos dos agrotóxicos a estudantes do IFMT. 2015. Disponível em: <http://www.ufmt.br/ufmt/site/noticia/visualizar/23217/Rondonopolis>. Acesso em: 10 dezembro 2016.
} 
excede o LMR ou não é autorizado para a cultura, existe uma irregularidade. Entretanto, a ANVISA salienta que não necessariamente o consumidor estará em risco (ANVISA, 2016).

Já os efeitos crônicos de correntes da exposição aos agrotóxicos são aqueles que se manifestam depois de passados longos períodos em que ocorreu a exposição. Por outro lado, os efeitos agudos são consequência de uma exposição única ou no curto prazo, resultando usualmente em dados clínicos evidentes. De Acordo com Romão e Vieira (2004) ${ }^{14}$ essas ocorrências podem ser tanto acidentais quanto intencionais. Os sinais de intoxicação aguda, em razão à exposição aos agrotóxicos, incluem transtornos de visão, vômitos, ansiedade, confusão mental, hipertensão arterial, efeitos neurológicos diversos podendo culminar em mortalidade (Palma e Lourencetti, 2011).

O Sistema Nacional de Informações Tóxico-Farmacológicas (Sinitox) tem como principal atribuição coordenar a coleta, a compilação, a análise e a divulgação dos casos de intoxicação e envenenamento notificados no país. Os dados da região centro-oeste no ano de 2013, último relatório para a região, apresentam 349 casos de intoxicação humana por agrotóxicos/uso agrícola e 338 notificações para agrotóxicos/doméstico (SINITOX, 2013) ${ }^{15}$. As intoxicações exógenas por agrotóxicos, por estado e o Distrito Federal, registradas entre 2007 e 2014 apontam o total de 34 147 casos de intoxicações (PORTAL BRASIL, 2016) ${ }^{16}$.

Os registros são realizados pelos Centros de Informação e Assistência Toxicológica (Ciats), localizados em vários estados brasileiros, parte deles integrantes da Rede Nacional de Centros de Informação e Assistência Toxicológica (Renaciat) (SINITOX, 2016) ${ }^{17}$. A problemática aqui esbarra na ausência de notificação ou subnotificação, pois, é sabido que as subnotificações por agrotóxicos são práticas recorrentes nos órgãos de atendimento público de saúde.

A burocracia, a inapetência de profissionais e sistemas automatizados falhos podem ser causas prováveis para essa realidade. Somem-se a isto, os casos em

\footnotetext{
${ }^{14}$ ROMÃO, M. R; VIEIRA, L. J. E. S. Tentativas de suicídio por envenenamento. Revista Brasileira em Promoção da Saúde, v. 17, p. 14-20, 2004.

${ }^{15}$ SINITOX. Dados de Intoxicação. Disponível em < https://sinitox.icict.fiocruz.br/dados-nacionais> Acesso em: 27 janeiro 2018.

${ }^{16}$ PORTAL BRASIL. Agricultura familiar produz $70 \%$ dos alimentos consumidos por brasileiro.

Disponível em: <http://www.brasil.gov.br/economia-e-emprego/2015/07/agricultura-familiar-produz-70dos-alimentos-consumidos-por-brasileiro>. Acesso em: 03 dezembro 2016.

${ }^{17}$ SISTEMA NACIONAL DE INFORMAÇÕES TÓXICO-FARMACOLÓGICAS-Sinitox. Missão.

Disponível em: <http://sinitox.icict.fiocruz.br/missao>. Acesso em 08 dezembro 2016.
} 
que as pessoas intoxicadas são levadas ao atendimento em centros privados ou são atendidas na própria localidade da intoxicação, constituindo outra forma de subnotificação.

Os agrotóxicos, enquanto produtos, são utilizados em quantidades insustentáveis ao equilíbrio dos ecossistemas e no concernente ao impacto sobre a saúde humana. Um ponto importante e preocupante a ser considerado é a legislação brasileira corrente de incentivo econômico para a aquisição de agrotóxicos. O convênio ICMS 100/971, com fulcro na Lei complementar nํ24/1975 reduz a base de cálculo do imposto sobre circulação de mercadorias e serviços (ICMS) entre 30 e 60\% aos insumos agropecuários que específica (BRASIL, 1975) ${ }^{18}$. Tal política pública, expressa claramente a submissão de países subdesenvolvidos e em desenvolvimento a economia capitalista, pautada na exploração de recursos naturais, produção e consumo, orientada pelo livre mercado.

Os dados de monitoramento do PARA revelam que amostras de algumas culturas apresentam resíduos de vários ingredientes ativos (ANVISA, 2016). Tal constatação reforça a necessidade de melhoria na formação dos produtores rurais e o acompanhamento do uso de agrotóxicos na agricultura brasileira, de modo a garantir as Boas Práticas Agrícolas (BPA). O uso de um ou mais agrotóxicos em culturas para as quais eles não estão autorizados, sobretudo aqueles em fase de reavaliação ou de descontinuidade programada devido a sua relevância toxicológica, pode acarretar em maior exposição ocupacional e gerar risco à saúde do trabalhador rural e de toda a população (ANVISA, 2013).

Alternativas precisam ser buscadas e adotadas para a redução da utilização de agrotóxicos na produção de alimentos para humanos e animais. A adoção e a incorporação de sistemas sustentáveis para produção vegetal e animal precisam ser buscadas continuamente. $\mathrm{O}$ fortalecimento da agricultura familiar; o incentivo público para a produção de alimentos orgânicos; a integração de sistemas como lavourapecuária-floresta são caminhos possíveis.

O pequeno agricultor ocupa hoje papel decisivo na cadeia produtiva que abastece o mercado brasileiro. A agricultura familiar é a principal responsável pelos ingredientes que chegam à mesa das famílias brasileiras representando cerca de $70 \%$

\footnotetext{
${ }^{18}$ BRASIL. Lei complementar no 24 , de 07 de janeiro de 1975. Dispõe sobre os convênios para a concessão de isenções do imposto sobre operações relativas à circulação de mercadorias, e dá outras providências. Diário Oficial da União, Brasília, DF, 09 jan. 1975.
} 
dos alimentos consumidos em todo o país (PORTAL BRASIL, 2016). Assim, a difusão de tecnologias para as pequenas propriedades rurais voltadas para a produção orgânica, agroecológica e sustentável se faz imprescindível para reverter às estatísticas de utilização massiva de agrotóxicos nas plantações. Desta forma, almeja-se a restauração da saúde do ambiente e do trabalhador.

O incentivo econômico e o fortalecimento da agricultura pautada na produção orgânica e agroecológica deveria ser uma alternativa ao sistema de produção vigente para a obtenção de alimentos. A falta de políticas públicas de incentivo a esse formato de produção, associado às dificuldades que se tem hoje em dia de produzir organicamente em função da expansão de áreas agricultáveis para a produção da monocultura de grãos, limitam o acesso e o consumo desses alimentos pela população.

O sistema de integração lavoura-pecuária-floresta (iLPF) por meio de práticas e manejos propõem recuperar áreas degradadas, e tornar as áreas já utilizadas mais rentáveis evitando a abertura de novas fronteiras produtivas. Nesse sentido, são exemplos benéficos do sistema de iLPF a redução das plantas daninhas dentro do sistema, seguido, portanto da redução no uso de agrotóxicos, além da reciclagem de nutrientes.

\section{PERSPECTIVAS PARA A EDUCAÇÃO}

Um dos pressupostos da educação é a compreensão da sociedade e da realidade buscando transformá-las. Assim, no âmbito da expansão da fronteira agrícola brasileira, condicionada à utilização massiva de agrotóxicos nos plantios, a temática da saúde pública e ambiental ganham relevância e apresentam demandas à educação em seu papel de educar para a cidadania e a melhora da qualidade de vida. A realidade aqui exposta, que aponta para perspectivas futuras de cenários intoleráveis para a saúde do ambiente, e consequentemente para todas as formas de vida no planeta, necessita se considerada no ensino.

No ensino formal, a Educação Ambiental é um dos caminhos por meio do qual se propõe o diálogo, a reflexão e a ação diante das questões socioambientais. As diferentes modalidades que atendem às diversidades, dentre as quais a Educação do Campo, têm seus projetos de ensino direcionados às populações, de modo a contemplar as peculiaridades e demandas inerentes à cada realidade. Na Educação 
do Campo essa proposta almeja o ensino que venha ao encontro da sustentabilidade da relação homem-natureza (MATO GROSSO, 2012) ${ }^{19}$.

Em adição, na base diversificada do currículo da educação básica nacional, a Educação Ambiental é tema a ser abordado no ensino. Considerando o aqui exposto, é importante salientar que a Educação Ambiental necessita ser efetivada no âmbito de uma leitura ampliada da relação sociedade-natureza, do papel da economia no processo de exploração de recursos naturais e na expansão do agronegócio, das diferentes formas de desigualdade socioambiental decorrentes, da importância da atuação dos diferentes atores sociais com vistas à sustentabilidade.

No entanto, autores como Leff $(2013)^{20}$ e Loureiro (2012) ${ }^{21}$ afirmam que a temática do ambiente tem sido abordada nos diferentes programas de formação em uma perspectiva conservacionista/recursista, que dissocia homem e natureza, enfatizando questões de gestão ambiental no âmbito do descarte adequado de resíduos. Nesse sentido, os programas de formação em educação ambiental necessitam considerar a abordagem das questões ambientais relacionadas à agricultura, agrotóxicos e a saúde do trabalhador a partir de uma leitura ampliada da concepção de ambiente, entendendo este como espaço em que as relações entre a economia e o espaço natural impactam-se mutuamente e geram conseqüências que necessitam ser analisadas e repensadas.

A construção de um novo pensamento sobre o ambiente se faz necessária nesta sociedade contemporânea. Para que novos valores de ambiente e de sociedade possam emergir, é premente a emancipação das populações frente ao alheamento aos reais interesses do sistema econômico vigente.

\section{CONSIDERAÇÕES FINAIS}

Os riscos e os agravos que os agrotóxicos podem causar a saúde ambiental deveria ser debatido pelos diversos segmentos de representação social, dentre os quais a educação. Os processos produtivos onde a demanda é produzir,

\footnotetext{
${ }^{19}$ MATO GROSSO. Secretaria de Estado de Educação. Orientações Curriculares: concepções para a educação básica. Cuiabá: Gráfica print, 2012.

20 LEFF, E. Saber ambiental: sustentabilidade, racionalidade, complexidade, poder. Tradução Lúcia Mathilde Endlich Orth. 10. ed. Rio de Janeiro: Vozes, 2013.

${ }^{21}$ LOUREIRO, C. F. B. Trajetórias e fundamentos da educação ambiental. 4. ed. São Paulo: Cortez, 2012.
} 
independente de quem arcará com os danos originados, conduzem a situações insustentáveis para o ambiente.

Nesse cenário de utilização massiva de agrotóxicos, faz-se imprescindível aos órgãos responsáveis pela orientação aos produtores rurais, representados principalmente pelas instituições estaduais de extensão rural, difundir a informação com o objetivo de levar aos agricultores a importância e necessidade da utilização de Boas Práticas Agrícolas (BPA). Além disso, o ensino não-formal em educação ambiental necessita ser ampliado para esse público, em uma perspectiva que possibilite a formação crítica.

A Educação Ambiental Crítica contribui para a formação crítica, reflexiva e propositiva acerca da relação sociedade-economia-natureza. Por meio do exercício da cidadania, da organização e da ação da coletividade, vislumbra-se um caminho possível para promover a transformação social com vistas a sustentabilidade e a melhora da qualidade de vida das populações.

\section{REFERÊNCIAS}

AGÊNCIA NACIONAL DE VIGILÂNCIA SANITÁRIA-ANVISA. Programa de Análise de Resíduos de Agrotóxicos em Alimentos (PARA). Relatório de Atividades de 2011 e 2012. Brasília, out., 2013. 45p. Disponível em:

<http://portal.anvisa.gov.br/documents/111215/117818/Relat\%25C3\%25B3rio\%252B PARA\%252B2011-12\%252B-\%252B30_10_13_1.pdf/d5e91ef0-4235-4872-b18099610507d8d5>. Acesso em: 09 dezembro 2016.

AGÊNCIA NACIONAL DE VIGILÂNCIA SANITÁRIA-ANVISA. Programa de Análise de Resíduos de Agrotóxicos em Alimentos (PARA). Relatório das análises de amostras monitoradas no período de 2013 a 2015. Brasília, nov., 2016. 246p. Disponívelem:<http://portal.anvisa.gov.br/documents/111215/0/Relat\%C3\%B3rio+PA RA+20132015_VERS\%C3\%83O-FINAL.pdf/494cd7c5-5408-4e6a-b0e55098cbf759f8>. Acesso em: 08 dezembro 2016.

BRASIL. Lei complementar oㅡ 24, de 07 de janeiro de 1975. Dispõe sobre os convênios para a concessão de isenções do imposto sobre operações relativas à circulação de mercadorias, e dá outras providências. Diário Oficial da União, Brasília, DF, 09 jan. 1975.

. Lei no 7.802, de 11 de julho de 1989. Dispõe sobre a pesquisa, a produção, a embalagem e rotulagem, o transporte, o armazenamento, a comercialização, a propaganda comercial, a utilização, a importação, a exportação, o destino final dos resíduos e embalagens, o registro, a classificação, o controle, a inspeção e a fiscalização de agrotóxicos, seus componentes e afins, e dá outras providências. In: 
Legislação federal de agrotóxicos e afins. Brasília (DF): Ministério da Agricultura e do Abastecimento; 1998. p. 7-13.

INSTITUTO CIDADE AMIGA. Pesquisador Wanderlei Pignati fala sobre impactos dos agrotóxicos a estudantes do IFMT. 2015. Disponível em:

<http://www.ufmt.br/ufmt/site/noticia/visualizar/23217/Rondonopolis>. Acesso em: 10 dezembro 2016.

LEFF, E. Saber ambiental: sustentabilidade, racionalidade, complexidade, poder. Tradução Lúcia Mathilde Endlich Orth. 10. ed. Rio de Janeiro: Vozes, 2013.

LOUREIRO, C. F. B. Trajetórias e fundamentos da educação ambiental. 4. ed. São Paulo: Cortez, 2012.

MANCUSO, M. A. C.; NEGRISOLI, E.; PERIM, L. Efeito residual de herbicidas no solo ("Carryover"). Revista Brasileira de Herbicidas, v. 10, n. 2, p. 151-164, mai./ago., 2011.

MATO GROSSO. Secretaria de Estado de Educação. Orientações Curriculares: concepções para a educação básica. Cuiabá: Gráfica print, 2012.

PALMA, D. C. A.; LOURENCETTI, C. Agrotóxicos em água e alimentos: risco à saúde humana. REVISTA UNIARA, v. 14, n. 2, p. 7-21, dez., 2011.

PIGNATI, W. A.; MACHADO, J. M. H.; CABRAL, J. F. Acidente rural ampliado: o caso das "chuvas"de agrotóxicos sobre a cidade de Lucas do Rio Verde - MT.

Ciência \& Saúde Coletiva, v. 12, n. 1, p.105-114, 2007.

PORTAL BRASIL. Agricultura familiar produz $\mathbf{7 0} \%$ dos alimentos consumidos por brasileiro. Disponível em: <http://www.brasil.gov.br/economia-eemprego/2015/07/agricultura-familiar-produz-70-dos-alimentos-consumidos-porbrasileiro>. Acesso em: 03 dezembro 2016.

ROMÃO, M. R; VIEIRA, L. J. E. S. Tentativas de suicídio por envenenamento. Revista Brasileira em Promoção da Saúde, v. 17, p. 14-20, 2004.

SANCHES, S. M. et al. Pesticidas e seus respectivos riscos associados à contaminação da água. Pesticidas: Revista de Ecotoxicologia e Meio Ambiente, Curitiba, v. 13, p. 53-58, jan./dez., 2003.

SISTEMA NACIONAL DE INFORMAÇÕES TÓXICO-FARMACOLÓGICAS-Sinitox. Casos registrados de intoxicação humana por agente tóxico e centro. Região centro-oeste, 2013. Disponível em:

$<$ http://sinitox.icict.fiocruz.br/sites/sinitox.icict.fiocruz.br/files//CO\%20Tabela1_2013.p df>. Acesso em 08 dezembro 2016.

SISTEMA NACIONAL DE INFORMAÇÕES TÓXICO-FARMACOLÓGICAS-Sinitox. Missão. Disponível em: <http://sinitox.icict.fiocruz.br/missao>. Acesso em 08 dezembro 2016. 
SPADOTTO, C. A. Abordagem interdisciplinar na avaliação ambiental de agrotóxicos. Revista Núcleo de Pesquisa Interdisciplinar, São Manuel, p. 1-9, 2006. 